\title{
Hydroxyapatites as versatile inorganic hosts of unusual pentavalent manganese cations
}

\author{
Aurea Varela, ${ }^{1}$ Isabel Gómez-Recio, ${ }^{1}$ Laura Serrador, ${ }^{1}$ María Hernando, ${ }^{1}$ Emilio \\ Matesanz, ${ }^{2}$ Almudena Torres-Pardo, ${ }^{1,3}$ María Teresa Fernández-Díaz, ${ }^{4}$ Jose L. \\ Martínez, ${ }^{5}$ Francisco Gonell, ${ }^{6}$ Gwenaelle Rousse, ${ }^{7}$ Clément Sanchez, ${ }^{6}$ Christel Laberty- \\ Robert, ${ }^{6}$ David Portehault, ${ }^{6 *}$ José M. González-Calbet, ${ }^{1,3}$ and Marina Parras ${ }^{1 *}$
}

1 Departamento de Química Inorgánica, Facultad de Químicas, Universidad Complutense de Madrid, 28040-Madrid, Spain.

${ }^{2}$ Unidad de Difracción de Rayos X. Centro de Asistencia a la Investigación de Técnicas Físicas y Químicas. Universidad Complutense de Madrid, 28040-Madrid, Spain.

3 ICTS ELECMI Centro Nacional de Microscopía Electrónica, Universidad Complutense de Madrid, 28040 Madrid, Spain

${ }^{4}$ Institut Laue-Langevin, 71 avenue des Martyrs, CS 20156, 38042 Grenoble cedex 9, France

${ }^{5}$ Instituto de Ciencia de Materiales de Madrid, CSIC, Sor Juana Inés de la Cruz s/n, 28049-Madrid, Spain

${ }^{6}$ Sorbonne Université, CNRS, Collège de France, Laboratoire Chimie de la Matière Condensée de Paris, 4 Place de Jussieu, 75005 Paris, France

${ }^{7}$ PSL Research University, Sorbonne Université, Collège de France, Chimie du Solide et de 1'Energie, UMR 8260, Collège de France, 11 place Marcelin Berthelot, 75007 Paris, France

* Corresponding author:

David Portehault (david.portehault@sorbonne-universite.fr), Marina Parras (mparras@ucm.es) 


\section{SUPPORTING INFORMATION}

\section{SEM experiments}

Figure S1. SEM micrograph corresponding to HApMn sample.

\section{Structural analysis by $\mathrm{X}$-ray and neutron diffraction}

Figure S2. Profile matching refinement of the X-ray diffraction data of the: a) HApMn and b) HApMnSi samples.

Figure S3. Difference Fourier maps (excluding hydroxyl $H$ ) of the section $x=0$ for a) HApMn and b) HApMnSi. The map shows the positions in which the most prominent negative scattering density appears. The hydrogen atoms of the $\mathrm{OH}$ groups should be located at those positions.

Table S1. Structural parameters from the refinement for HApMn and HApMnSi Hydroxyapatites of neutron powder diffraction data.

Table S2. Selected interatomic distances $(\AA)$ in HApMn and HApMnSi Hydroxyapatites.

\section{TEM experiments}

Figure S4. HRTEM of HApMnSi sample.

Figure S5. Evaluation of beam-damage for HApMnSi crystals.

\section{HAADF image simulations}

Table S3. Parameters for the simulation of HAADF images of HApMnSi material along [001] projection.

Figure S6. Simulation of HAADF images of HApMnSi material along [001] projection.

\section{Optimization of the STEM- EELS experimental conditions}

Room temperature experiments

Figure S7. Evaluation of the degradation of the HApMnSi sample under the electron beam at room temperature.

\section{Low temperature experiments}

Figure S8. Evaluation of the degradation of the HApMn sample under the electron beam. 


\section{EELS Mn-L2,3 signal analysis}

Table S4. Energy loss $(\mathrm{eV})$ and $\mathrm{I}\left(\mathrm{L}_{3}\right) / \mathrm{I}\left(\mathrm{L}_{2}\right)$ ratio of the $\mathrm{Mn}-\mathrm{L}_{2,3}$ edges for $\mathrm{Ba}_{3} \mathrm{Mn}_{2} \mathrm{O}_{8}$, $\mathrm{Ca}_{2} \mathrm{Mn}_{3} \mathrm{O}_{8}, \mathrm{LaMnO}_{3}, \mathrm{Ca}_{2} \mathrm{Mn}_{3} \mathrm{O}_{5}, \mathrm{HApMnSi}$ and $\mathrm{FApMnSi}$ samples

\section{Neutron diffraction data refinement of the fluorinated FApMn sample}

Table S5. Structural parameters from the refinement for FApMnSi and FApMn Fluoroapatites from neutron powder diffraction data.

Table S6. Selected interatomic distances $(\AA)$ in FApMnSi and FApMn Fluoroapatites from powder neutron diffraction data.

Table S7. Comparison of cell parameters and Sr2-(F, OH) bond distances in the $\mathrm{Mn}(\mathrm{V})$ hydroxy- and florinated apatites

\section{Magnetic behaviour HApMn and FApMn apatites.}

Table S8. Paramagnetic moments calculated and Curie-Weiss temperatures for hydroxy and fluor-ApMn.

Figure S9. Temperature dependence of the magnetic susceptibility for HApMn and FApMn samples.

Figure S10. Field dependence of the magnetization at 5 and $200 \mathrm{~K}$ for HApMn and FApMn samples

\section{IX.Thermal stability study}

Figure S11. Thermogravimetric analysis of HApMnSi sample.

Figure S12. In situ high temperature XRD of the HApMnSi sample.

Figure S13 Thermogravimetric analysis of HApMn sample.

Figure S14. In situ high temperature XRD of the HApMn sample.

Figure S15. XRD of the pellets as prepared, calcined at $450{ }^{\circ} \mathrm{C}$ and after the conductivity measurement. 


\section{SEM experiments}

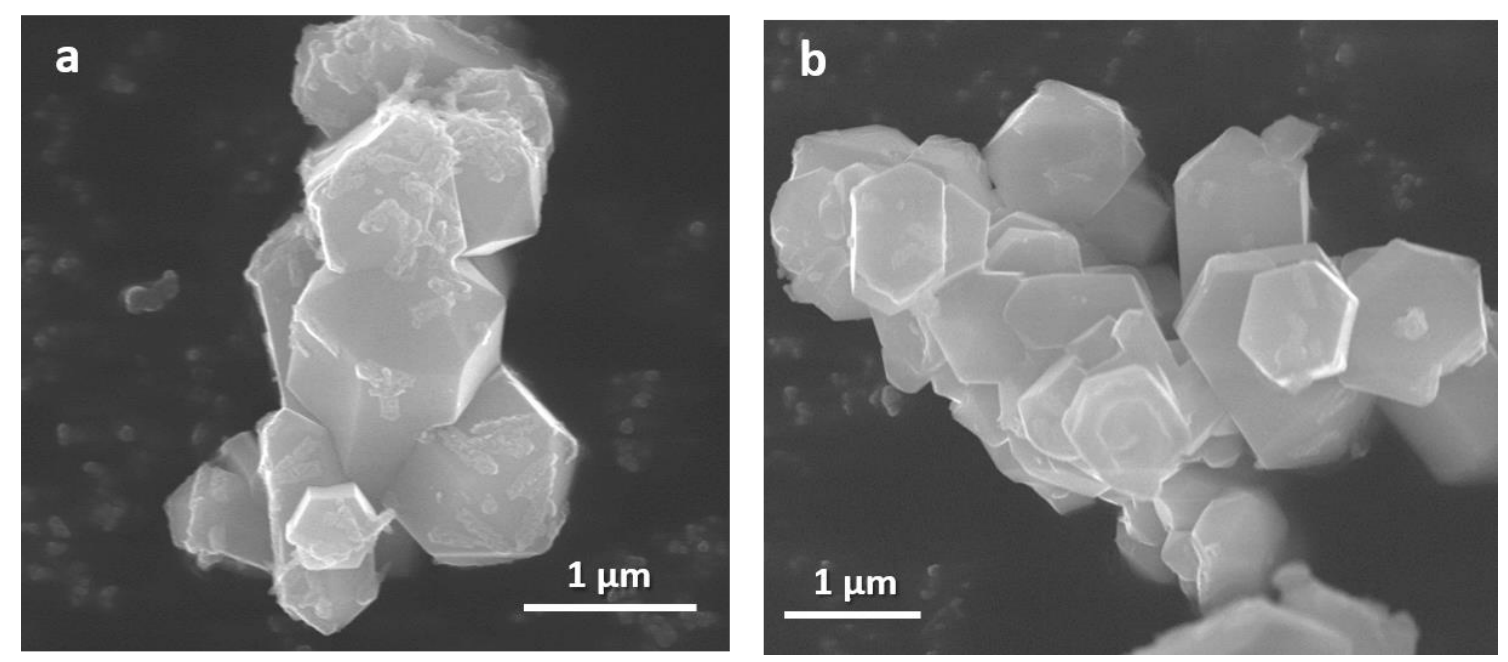

Figure S1. SEM micrograph corresponding to HApMn sample. Similar hexagonal shaped particles where observed for HApMnSi sample. 


\section{Structural analysis by X-ray and neutron diffraction}
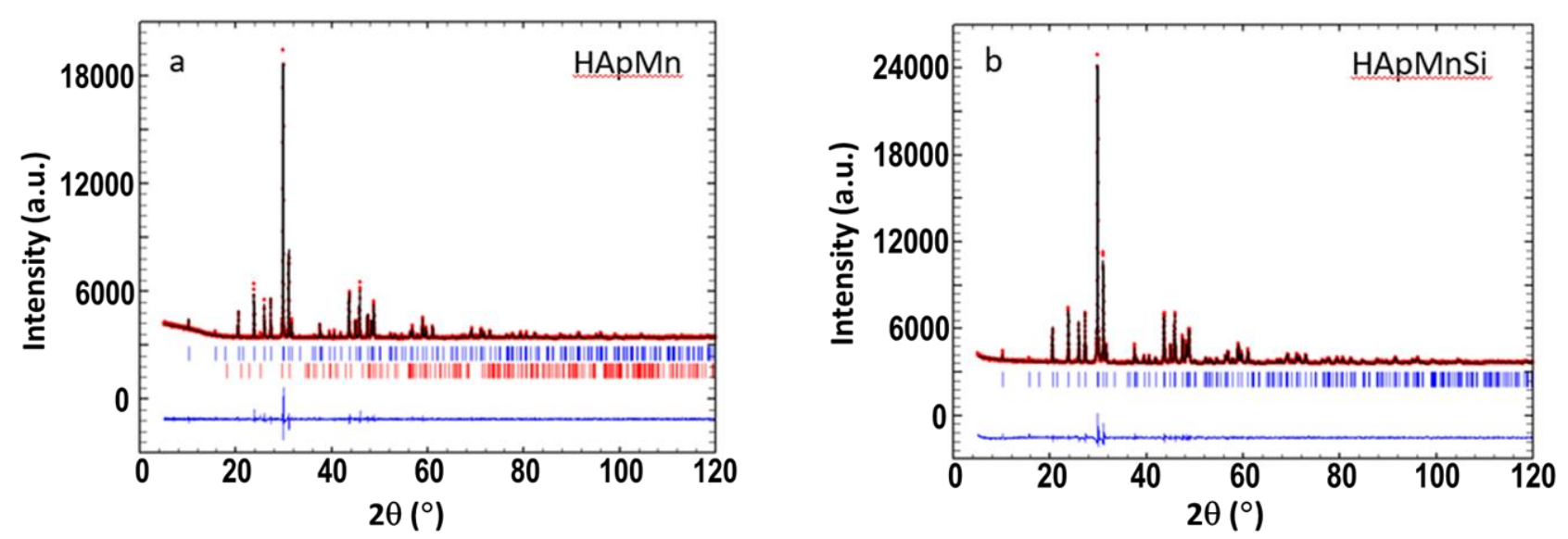

Figure S2. Profile matching refinement of the X-ray diffraction data of (a) HApMn, $\mathrm{Rp}=4.52, \chi^{2}=1.83$ (red tick-marks correspond to the maximum of the of $\mathrm{SrCO}_{3}$ phase as impurity) and (b) HApMnSi, $\mathrm{Rp}=4.07, \chi^{2}=2.41$. 
Table S1. Structural parameters from the refinement of neutron powder diffraction data for HApMn and HApMnSi hydroxyapatites.

\begin{tabular}{|c|c|c|c|c|c|}
\hline Atom & $\mathbf{X}$ & $\mathbf{y}$ & $\mathbf{Z}$ & $\mathbf{B}\left(\AA^{2}\right)$ & Occ \\
\hline \multicolumn{6}{|l|}{ Sr1 } \\
\hline$* \mathrm{Mn}$ & $1 / 3$ & $2 / 3$ & $0.0027(4)$ & $0.77(4)$ & 1 \\
\hline$* * \mathrm{Mn}, \mathrm{Si}$ & $1 / 3$ & $2 / 3$ & $0.0040(5)$ & $1.36(6)$ & 1 \\
\hline \multicolumn{6}{|l|}{$\mathrm{Sr} 2$} \\
\hline Mn & $0.2422(2)$ & $0.9891(3)$ & 0.25 & $0.63(3)$ & 1 \\
\hline $\mathrm{Mn}, \mathrm{Si}$ & $0.2403(4)$ & $0.9862(4)$ & 0.25 & $1.27(4)$ & 1 \\
\hline \multicolumn{6}{|l|}{$\operatorname{Mn}(\mathbf{S i})$} \\
\hline $\mathrm{Mn}$ & $0.4004(4)$ & $0.3654(4)$ & 0.25 & $0.34(7)$ & 1 \\
\hline $\mathrm{Mn}, \mathrm{Si}$ & $0.3994(7)$ & $0.3646(6)$ & 0.25 & $1.15(15)$ & a \\
\hline \multicolumn{6}{|l|}{01} \\
\hline Mn & $0.3204(3)$ & $0.4834(3)$ & 0.25 & $0.89(4)$ & 1 \\
\hline $\mathrm{Mn}, \mathrm{Si}$ & $0.3231(4)$ & $0.4841(4)$ & 0.25 & $1.40(6)$ & 1 \\
\hline \multicolumn{6}{|l|}{$\mathbf{O 2}$} \\
\hline $\mathrm{Mn}$ & $0.5935(3)$ & $0.4675(3)$ & 0.25 & $0.81(4)$ & 1 \\
\hline $\mathrm{Mn}, \mathrm{Si}$ & $0.5923(4)$ & $0.4674(4)$ & 0.25 & $1.57(7)$ & 1 \\
\hline \multicolumn{6}{|l|}{$\mathbf{O 3}$} \\
\hline $\mathrm{Mn}$ & $0.3455(2)$ & $0.2506(2)$ & $0.06978(20)$ & $1.50(3)$ & 1 \\
\hline $\mathrm{Mn}, \mathrm{Si}$ & $0.3446(3)$ & $0.2502(3)$ & $0.0699(3)$ & $2.02(5)$ & 1 \\
\hline \\
\hline $\mathrm{Mn}$ & 0 & 0 & $0.1906(7)$ & $1.53(9)$ & 0.5 \\
\hline $\mathrm{Mn}, \mathrm{Si}$ & 0 & 0 & $0.1871(11)$ & $2.4(2)$ & $0.421(9)$ \\
\hline \multicolumn{6}{|l|}{$\mathbf{H}$} \\
\hline Mn & 0 & 0 & $0.0624(12)$ & $1.53(9)$ & 0.5 \\
\hline $\mathrm{Mn}, \mathrm{Si}$ & 0 & 0 & $0.0596(17)$ & $2.4(2)$ & $0.421(9)$ \\
\hline $\begin{array}{l}\text { Mn: } \\
\text { Mn,Si: }\end{array}$ & $\begin{array}{l}a= \\
a=\end{array}$ & $\begin{array}{l}293(9) \AA \\
720(16)\end{array}$ & $\begin{array}{r}7.45254(9) \\
7.44779(1\end{array}$ & $\begin{aligned} c / a & =0 . \\
c / a & =0 .\end{aligned}$ & \\
\hline
\end{tabular}

$* \mathrm{Sr}_{5}\left(\mathrm{MnO}_{4}\right)_{3} \mathrm{OH}(\mathbf{H A p M n})$

** $\mathrm{Sr}_{5}\left(\left(\mathrm{Mn}_{0.947(6)} \mathrm{Si}_{0.053(6)}\right) \mathrm{O}_{4}\right)_{3}(\mathrm{OH})_{0.84(2)}(\mathbf{H A p M n S i})$

${ }^{\mathrm{a}} \mathrm{Mn}: \mathrm{Si}=0.947(6): 0.053(6)$;

Fit parameters: HApMn: $\quad \mathrm{R}_{\mathrm{B}}=2.95, \mathrm{R}_{\mathrm{p}}=1.42, \mathrm{R}_{\mathrm{wp}}=1.89, \chi^{2}=3.98$;

HApMnSi: $\mathrm{R}_{\mathrm{B}}=2.73, \mathrm{R}_{\mathrm{p}}=1.27, \mathrm{R}_{\mathrm{wp}}=1.70, \chi^{2}=2.64$;

In both apatites, the same Biso value for $\mathrm{H}$ and $\mathrm{O}_{\mathrm{H}}$ atoms was considered.

Mn fully occupies the $6 \mathrm{~h}$ Wyckoff positions (x, y, 0.25) in the HApMn sample. The occupancies of the $\mathrm{Mn} / \mathrm{Si}$ were constrained to be OccMn+OccSi=1 during refinements in HApMnSi.

In the HApMnSi, the occupation of $\mathrm{H}$ and $\mathrm{O}_{\mathrm{H}}$ atoms was fixed to the same value to form $\mathrm{OH}$ groups. The distance $\mathrm{O}_{\mathrm{H}}-\mathrm{H}$ was soft constrained to $0.93 \AA$ value. Besides, the $\mathrm{Si}$ and $\mathrm{OH}$ group occupations were correlated during the refinement according to the stoichiometry of the sample: $\mathrm{Sr}_{5}\left[\left(\mathrm{Mn}_{1-\mathrm{x}} \mathrm{Si}_{\mathrm{x}}\right) \mathrm{O}_{4}\right]_{3}(\mathrm{OH})_{1-3 \mathrm{x}}$ 
CIF files for HApMn and HApMnSi have been deposited at joint CCDC/Fiz Karlsruhe deposition service with deposition numbers CSD-2038883 and CSD-2038884, respectively. Structure data can be retrieved through their Access Structure service at https://www.ccdc.cam.ac.uk/structures.

Table S2. Selected interatomic distances $(\AA)$ in HApMn and HApMnSi Hydroxyapatites from neutron powder diffraction data.

\begin{tabular}{|c|c|c|}
\hline \multicolumn{2}{|c|}{ HApMn } & HApMnSi \\
\hline M-O1 & $1.717(6)$ & $1.702(9)$ \\
M-O2 & $1.665(4)$ & $1.665(7)$ \\
M-O3x2 & $1.668(3)$ & $1.665(4)$ \\
& & \\
Sr1-O1 x3 & $2.551(3)$ & $2.547(5)$ \\
Sr1-O2 x3 & $2.614(3)$ & $2.626(4)$ \\
Sr1-O3 x3 & $2.925(2)$ & $2.936(3)$ \\
& & \\
Sr2-OH & $2.506(3)$ & $2.508(5)$ \\
Sr2-O1 & $2.772(4)$ & $2.771(6)$ \\
Sr2-O2 & $2.504(3)$ & $2.522(5)$ \\
Sr2-O3 x2 & $2.638(3)$ & $2.657(4)$ \\
Sr2-O3x2 & $2.5407(19)$ & $2.532(3)$ \\
\hline
\end{tabular}
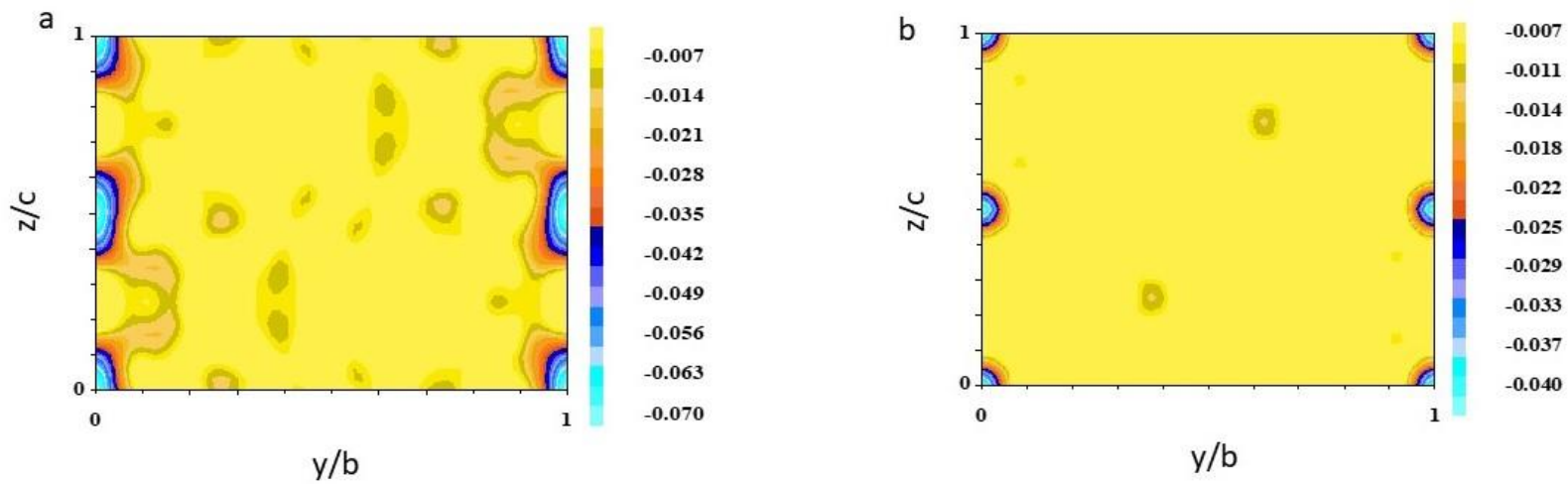

Figure S3. Difference Fourier maps (excluding hydroxyl $H$ ) of the section $x=0$ for (a) HApMn and (b) HApMnSi. The map shows the positions in which the most prominent negative scattering density appears. The hydrogen atoms of the $\mathrm{OH}$ groups should be located at these positions. 


\section{TEM experiments}

High Resolution Transmission Electron Microscopy (HRTEM) was performed on a total number of 10 crystals. Figures $\mathrm{S} 4 \mathrm{a}$ and $\mathrm{b}$ show a HRTEM image of a representative HApMnSi crystal and the corresponding Fast Fourier Transform pattern along [001] and [100], respectively. The reflection conditions are consistent with the hexagonal lattice with unit cell parameters $a=9.9559(1)$ and $c=7.45452(7) \AA$ (S.G. $\left.\mathrm{P}_{3} / \mathrm{m}\right)$. Notice the particularly high sensitivity of the material to the electron beam revealed in Figure S5 after 90-seconds of sequential recording between two HRTEM images. The loss of crystallinity due to beam damage is clearly observed in Figure S5b.

(a)
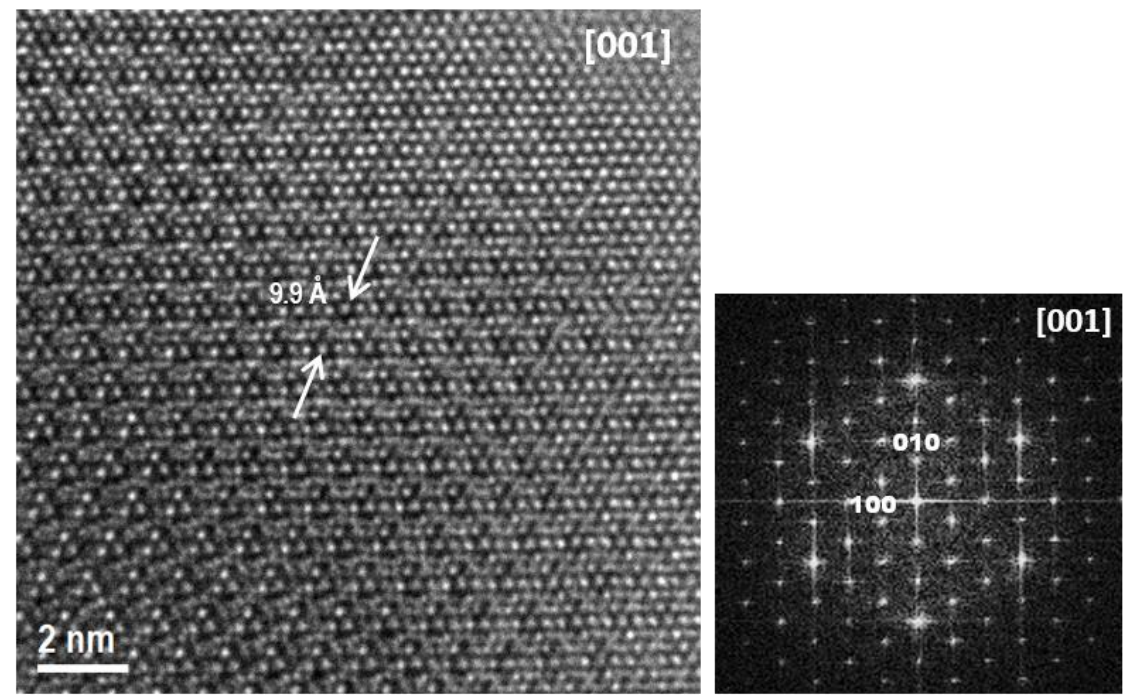

(b)
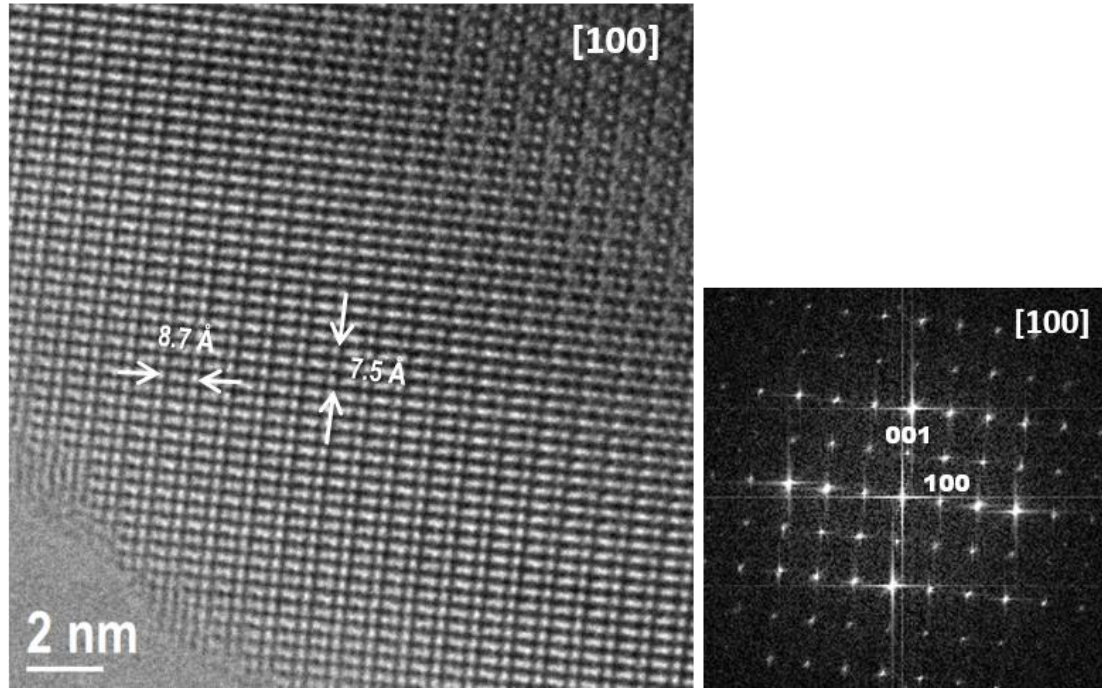

Figure S4. HRTEM images and the corresponding Fast Fourier Transform (FFT) pattern of a representative HApMnSi crystal along (a) [001] and (b) [100] projections. 


\section{(a)}
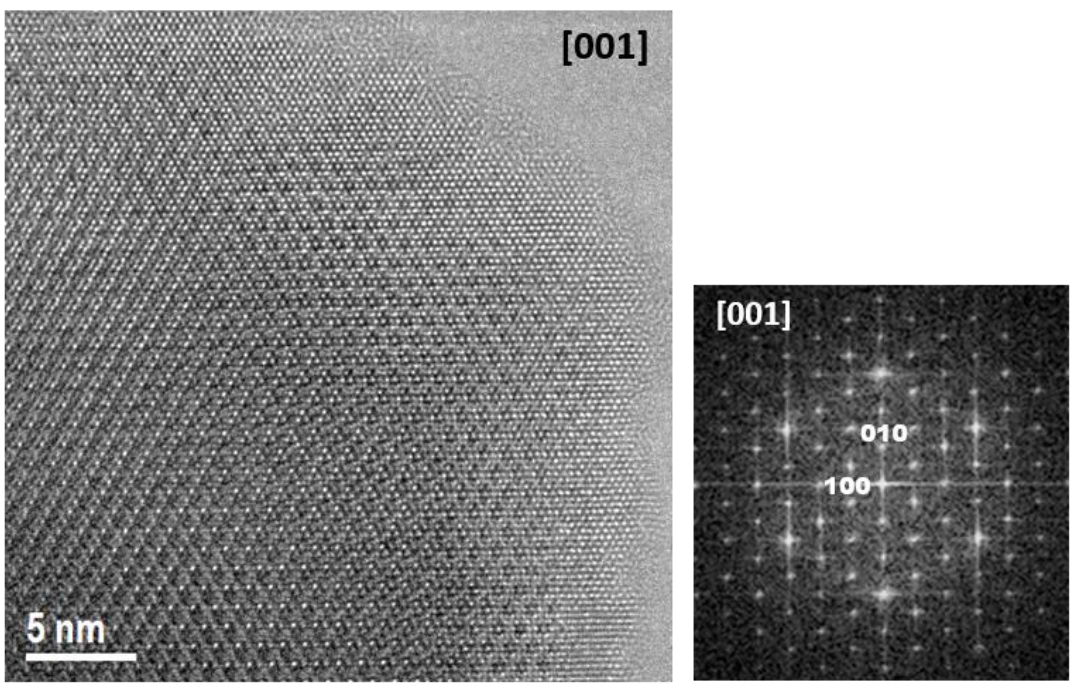

(b)
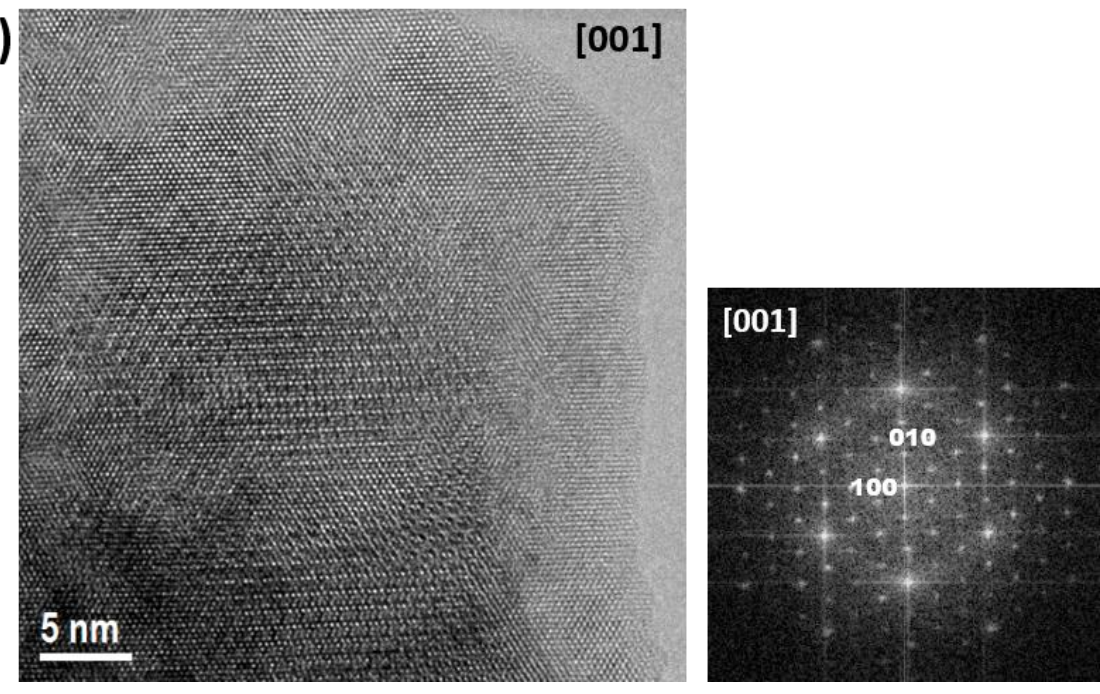

Figure S5. Evaluation of beam-damage. (a) HRTEM image and corresponding FFT of a representative HApMnSi crystal along [001] and (b) HRTEM and corresponding FFT recorded 90 seconds later. A clear loss of crystallinity is observed due to beam damage.

\section{HAADF image Simulations}

In order to qualitatively verify that $-\mathrm{OH}$ groups are responsible for the contrast observed at the Wyckoff position 4a in the HAADF images along the [001] projection, image simulations have been performed using the QSTEM software ${ }^{1}$. Atomic coordinates obtained from ND refinements were used as input data for simulation of HAADF images. Table S3 summarizes the parameters employed for image simulation. The simulated images obtained for different values of the sample thickness are shown in figure S6. The intensity profile tracked along the [110] direction evidences a non-zero intensity value at the $-\mathrm{OH}$ atomic positions as well as the difference of intensity between atomic columns occupied by $\mathrm{Mn}$ and $\operatorname{Sr}(2)$.

\footnotetext{
${ }^{1}$ s1. C. Koch, Ph.D. Thesis, Arizona State University, 2002
} 
Table S3. Parameters for the simulation of HAADF images of HApMnSi material along [001] projection

\begin{tabular}{|l|l|}
\hline \multicolumn{1}{|c|}{ Parameter } & \multicolumn{1}{c|}{ Value } \\
\hline Operating Voltage & $120 \mathrm{kV}$ \\
\hline $\mathrm{CS}$ & $0.05 \mathrm{~nm}$ \\
\hline $\mathrm{Cc}$ & $1 \mathrm{~nm}$ \\
\hline $\mathrm{dE}$ & $0.6 \mathrm{eV}$ \\
\hline Convergence angle & $35 \mathrm{mrad}$ \\
\hline TSD & 30 runs \\
\hline
\end{tabular}

(a)
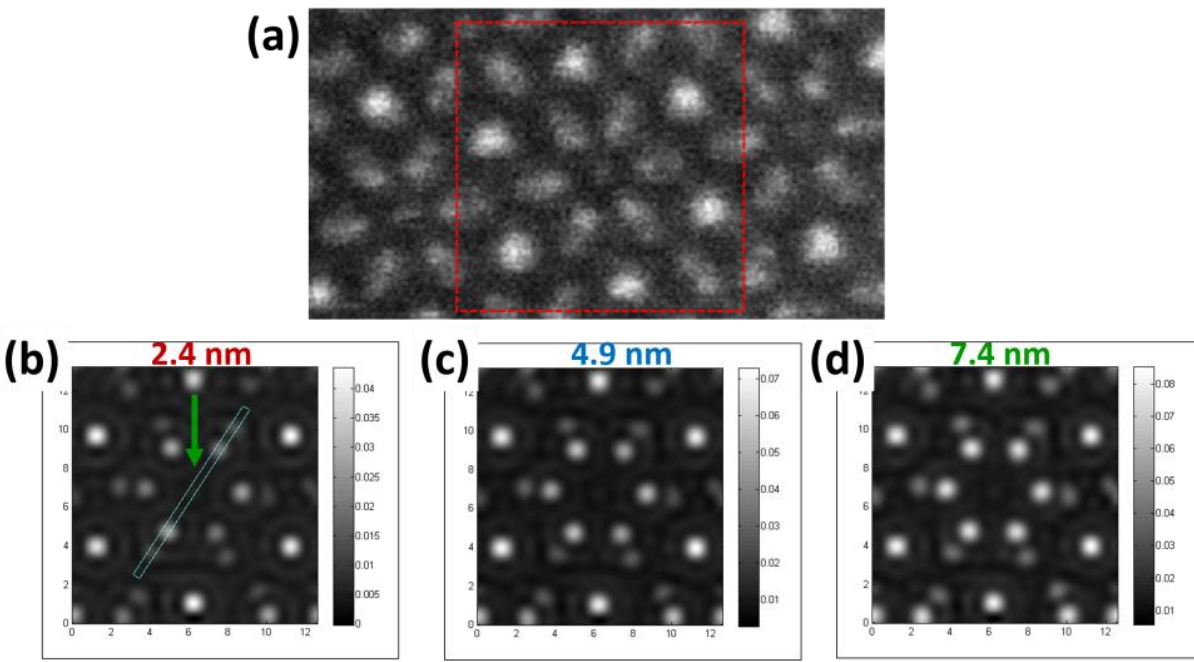

(e)

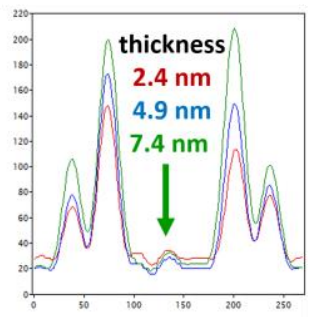

Figure S6. Simulation of HAADF images of HApMnSi material along [001] projection. (a) Raw HAADF image. The red square defines the simulated area. Simulated HAADF images for (b) $2.4 \mathrm{~nm}$ (c) $4.9 \mathrm{~nm}$ and (c) $7.4 \mathrm{~nm}$ thickness. (e) Intensity profiles along the [110] direction revealing the intensity at the $4 \mathrm{e}$ atomic positions occupied by the hydroxyl groups. 


\section{Optimization of the STEM- EELS experimental conditions}

\section{$\underline{\text { Room temperature experiments }}$}

In order to avoid damaging effect of the electron beam on the HApMnSi crystals, a set of preliminary tests were carried out to establish the experimental conditions allowing atom-resolved analysis without modifying neither the crystalline structure, nor the Mn oxidation state (Mn- $\mathrm{L}_{2,3}$ signal).

In this sense, we performed different STEM-EELS experiments while modifying the operation voltage in order to evaluate the degradation of the sample in HAADF images under the electron beam. Additionally, we evaluated changes in the Mn- $\mathrm{L}_{2,3}$ signals as a function of the dwell time that could also indicate damage of the sample. Taking into account these experimental limitations, we settled the operation voltage at $120 \mathrm{kV}$, and we limited the total acquisition time to $\sim 25 \mathrm{~s}$ to achieve good enough EELS signal/noise ratio as well as atomic spatial resolution over a total of $80-90 \mathrm{~nm}$. We compared the experimental data with reference data from $\mathrm{Ba}_{3} \mathrm{Mn}_{2} \mathrm{O}_{8}\left(\mathrm{Mn}^{5+}\right)$-acquired for first time during this work- $\mathrm{Sr}_{4} \mathrm{Mn}_{3} \mathrm{O}_{10}\left(\mathrm{Mn}^{4+}\right)^{2}, \mathrm{LaMnO}_{3}\left(\mathrm{Mn}^{3+}\right)^{3}$ and $\mathrm{Ca}_{2} \mathrm{Mn}_{3} \mathrm{O}_{5}\left(\mathrm{Mn}^{2+}\right)^{4}$.

Under the above conditions, we performed a sample stability test consisting in recording a series of spectra over the exact same area to evaluate changes in the position of the $\mathrm{Mn}-\mathrm{L}_{2,3}$ lines as a function of the beam exposure time. The analysis of the $\mathrm{Mn}-\mathrm{L}_{2,3}$ edges showed that the $\mathrm{Mn}-\mathrm{L}_{2,3}$ signals started changing after $25 \mathrm{~s}$ (Figure S7). After $30 \mathrm{~s}$ acquisition, a clear shoulder at lower energies is detected (pointed by an arrow), indicating a clear reduction of the sample due to beam damage. As a result of the sample stability test, we estimated that any feature that we observed on the Mn- $\mathrm{L}_{2,3}$ lines after a regular experiment (total exposition time $\sim 20-25 \mathrm{~s}$ ) could be considered a trustworthy data.

\footnotetext{
${ }^{2}$ I. N. González-Jiménez at al. Materials Horizon. 2018, 5, 480

${ }^{3}$ H. L. T. N'Goc at al. Advanced Materials 2017, 29, 1604745

${ }^{3}$ A. Mazarío-Fernández et al. Inorg. Chem. 2017, 56, 11753
} 


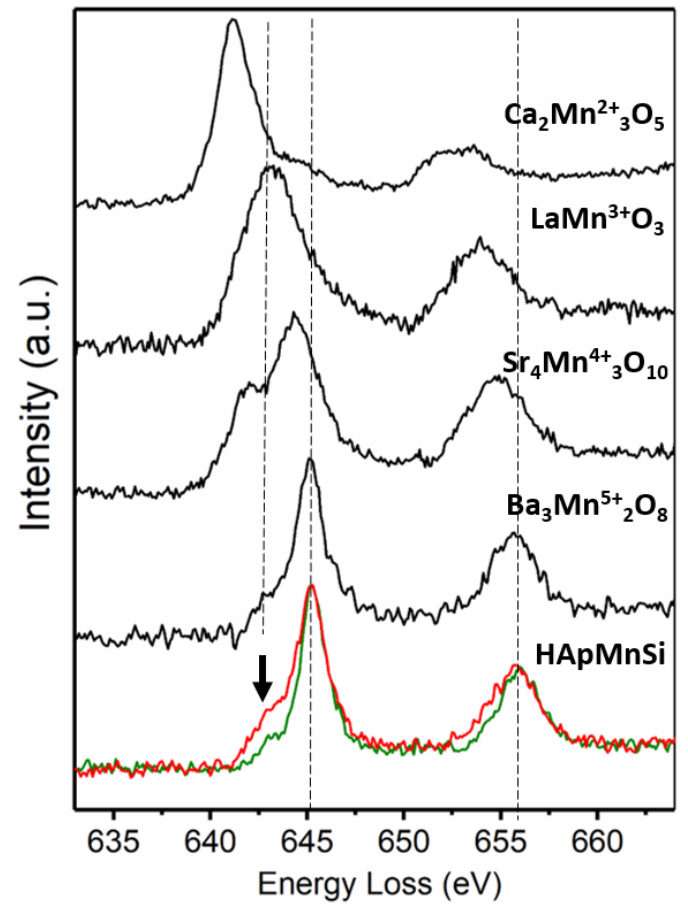

Figure S7. Degradation of the sample under the electron beam. EELS spectra of the references of $\mathrm{Mn}^{2+}, \mathrm{Mn}^{3+}, \mathrm{Mn}^{4+}$, and $\mathrm{Mn}^{5+}$ (black lines) oxidation states, HAPMnSi sample (green) showing expected $\mathrm{Mn}^{5+}$ (see manuscript), and HApMnSi sample after $30 \mathrm{~s}$ of exposition (red).

\section{Low Temperature Experiments}

The poor stability of the silicon-free and fluorinated samples under the electron beam prevented the acquisition of EELS spectra by reproducing the experiments optimized for HApMnSi sample. As can be observed in Figure S8, a clear degradation of the HApMn sample was observed with interaction of the electron beam with the sample. 


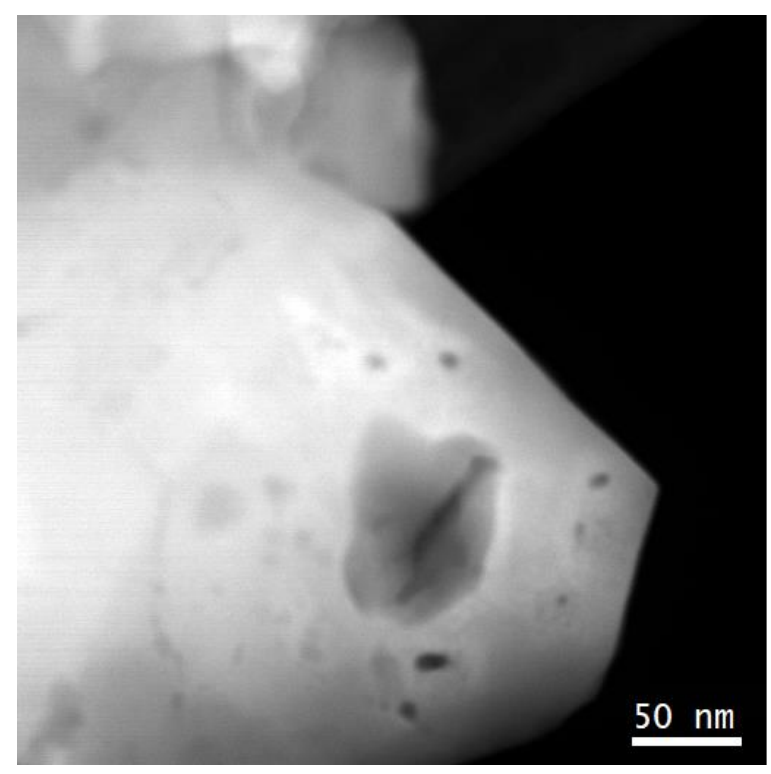

Figure S8. Low magnification HAADF image illustrating the high degradation of the HApMn sample because of its interaction with the electron beam at room temperature.

In order to improve the stability of the sample during EELS experiments, a liquid nitrogen-cooled specimen holder Gatan 636 was employed to record low-temperature EELS spectra. We operated at settled the operation voltage at $120 \mathrm{kV}$ at $-190,0{ }^{\circ} \mathrm{C}$, and we limited the total acquisition time to $\sim 10 \mathrm{~s}$ to achieve good enough EELS signal/noise ratio on the $\mathrm{Mn}-\mathrm{L}_{2,3}$ lines. Using these experimental conditions, we were able to acquire EELS data only from the fluorinated samples but the instability of the HApMn sample prevented the possibility to get information about Mn oxidation state of silicon-free sample.

\section{EELS Mn-L2,3 signal analysis}

In order to analyze the EELS experimental data obtained from the HApMnSi and FApMnSi samples, EELS spectra were recorded from four valence standard samples: $\mathrm{Ba}_{3} \mathrm{Mn}_{2} \mathrm{O}_{8}\left(\mathrm{Mn}^{5+}\right), \mathrm{Ca}_{2} \mathrm{Mn}_{3} \mathrm{O}_{8}\left(\mathrm{Mn}^{4+}\right), \mathrm{LaMnO}_{3}\left(\mathrm{Mn}^{3+}\right)$ and $\mathrm{Ca}_{2} \mathrm{Mn}_{3} \mathrm{O}_{5}\left(\mathrm{Mn}^{2+}\right)$. Notice that these standard samples shows two different $\mathrm{Mn}$ coordination to the oxygen atoms: octahedral $-\mathrm{MnO}_{6}$ - in the case of $\mathrm{Ca}_{2} \mathrm{Mn}_{3} \mathrm{O}_{8}\left(\mathrm{Mn}^{4+}\right), \mathrm{LaMnO}_{3}\left(\mathrm{Mn}^{3+}\right)$ and $\mathrm{Ca}_{2} \mathrm{Mn}_{3} \mathrm{O}_{5}$ $\left(\mathrm{Mn}^{2+}\right)$ and tetrahedral $-\mathrm{MnO}_{4}$ - in the case of $\mathrm{Ba}_{3} \mathrm{Mn}_{2} \mathrm{O}_{8}\left(\mathrm{Mn}^{5+}\right)$. Therefore, although the energy loss values can be compared for all the signals, the $I\left(L_{3}\right) / I\left(L_{2}\right)$ ratio should be compared only among those samples with similar Mn-O coordination. 
Table S4. Energy loss $(\mathrm{eV})$ and $\mathrm{I}\left(\mathrm{L}_{3}\right) / \mathrm{I}\left(\mathrm{L}_{2}\right)$ ratio of the $\mathrm{Mn}-\mathrm{L}_{2,3}$ edges for $\mathrm{Ba}_{3} \mathrm{Mn}_{2} \mathrm{O}_{8}$, $\mathrm{Sr}_{4} \mathrm{Mn}_{3} \mathrm{O}_{10}, \mathrm{LaMnO}_{3}, \mathrm{Ca}_{2} \mathrm{Mn}_{3} \mathrm{O}_{5}, \mathrm{HApMnSi}$ and FApMnSi samples

\begin{tabular}{|c|c|c|c|c|}
\hline Sample & Coordination & $E(e V) M n-L_{3}$ & $\begin{array}{l}E(e V) \\
M n-L_{2}\end{array}$ & $I\left(L_{3} / L_{2}\right)$ \\
\hline $\mathrm{Ca}_{2} \mathrm{Mn}^{2+}{ }_{3} \mathrm{O}_{5}$ & Octahedral- $\mathrm{MnO}_{6}$ & 641.2 & 652.3 & \\
\hline $\operatorname{LaMn}^{3+} \mathrm{O}_{3}$ & Octahedral-MnO & 643.2 & 654.0 & \\
\hline $\mathrm{Sr}_{4} \mathrm{Mn}^{4+}{ }_{3} \mathrm{O}_{10}$ & Octahedral-- $\mathrm{MnO}_{6}$ & 644.4 & 654.9 & \\
\hline $\mathrm{Ba}_{3} \mathrm{Mn}^{5+}{ }_{2} \mathrm{O}_{8}$ & Tetrahedral- $\mathrm{MnO}_{4}$ & 645.1 & 655.7 & 1.79 \\
\hline$H A p M n S i$ & Tetrahedral- $\mathrm{MnO}_{4}$ & 645.2 & 655.9 & 1.78 \\
\hline FApMnSi & Tetrahedral- $\mathrm{MnO}_{4}$ & 645.2 & 655.8 & 1.79 \\
\hline
\end{tabular}


VII.Neutron diffraction data refinement of the fluorinated samples

Table S5. Structural parameters from the NPD refinement for FApMn and FApMnSi fluoroapatites.

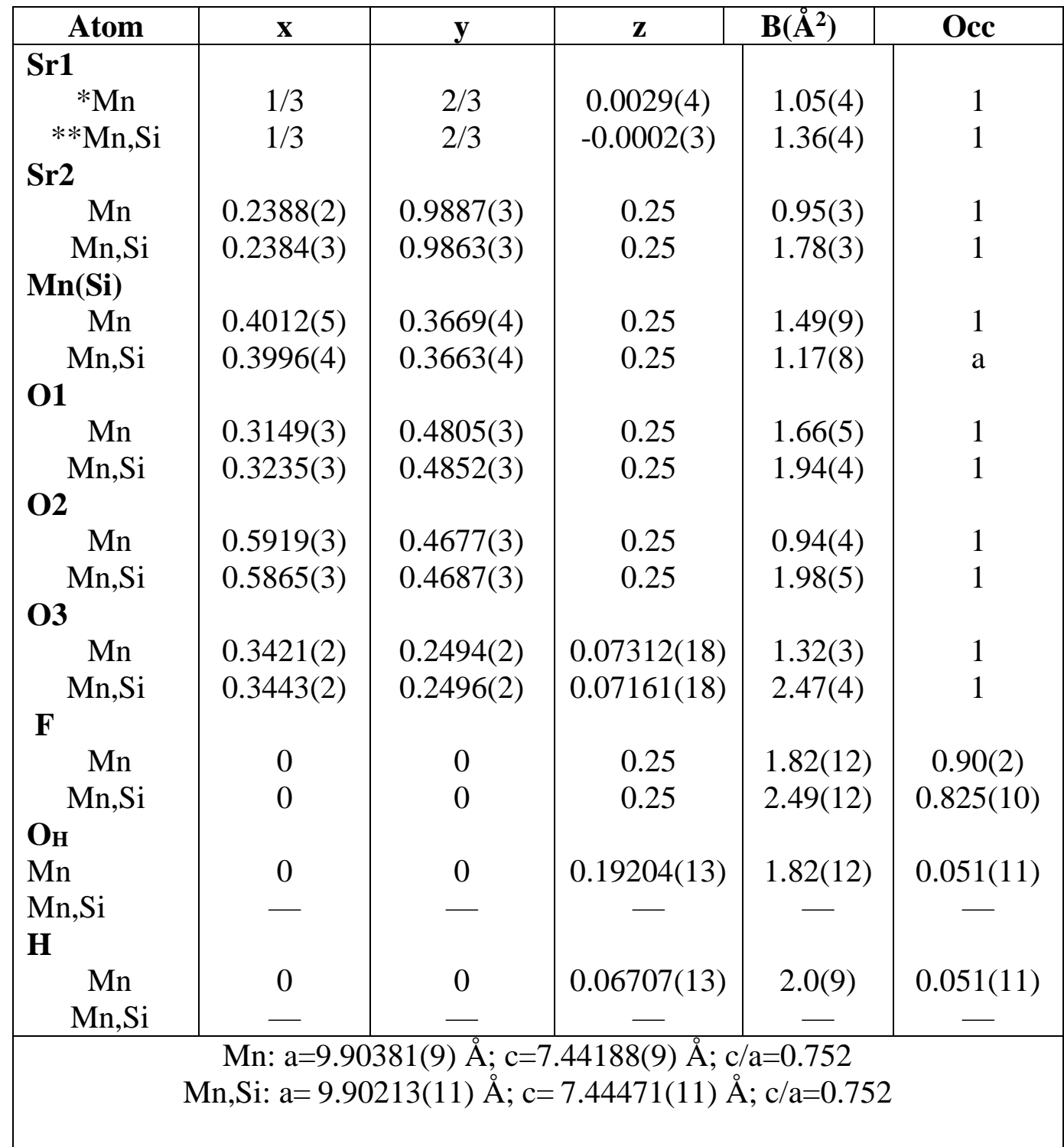

* $\mathrm{Sr}_{5}\left(\mathrm{MnO}_{4}\right)_{3} \mathrm{~F}_{0.90(2)}(\mathrm{OH})_{0.10(2)}(\mathbf{F A p M n})$

** $\mathrm{Sr}_{5}\left(\left(\mathrm{Mn}_{0.942(3)} \mathrm{Si}_{0.058(3)}\right) \mathrm{O}_{4}\right)_{3} \mathrm{~F}_{0.83(1)}(\mathbf{F A p M n S i})$

${ }^{\mathrm{a}} \mathrm{Mn}: \mathrm{Si}=0.942(3): 0.058(3)$

Fit parameters: FApMn: $\quad \mathrm{R}_{\mathrm{B}}=2.04, \mathrm{R}_{\mathrm{p}}=1.82, \mathrm{R}_{\mathrm{wp}}=2.44, \chi^{2}=4.72$

FApMnSi: $\mathrm{R}_{\mathrm{B}}=2.40, \mathrm{R}_{\mathrm{p}}=1.64, \mathrm{R}_{\mathrm{wp}}=2.27, \chi^{2}=4.07$;

Several restraints were considered in the refinement of the FApMnSi. The first one is that tetrahedra are fully occupied by $\mathrm{Mn}$ and $\mathrm{Si}$, i.e. OccMn+OccSi=1. The $\mathrm{Si}$ and $\mathrm{F}$ occupations were correlated during the refinement according to stoichiometry of the sample: $\mathrm{Sr}_{5}\left[\left(\mathrm{Mn}_{1-\mathrm{x}} \mathrm{Si}_{\mathrm{x}}\right) \mathrm{O}_{4}\right]_{3} \mathrm{~F}_{1-3 \mathrm{x}}$ 
In the FApMn sample: the occupation of $\mathrm{H}$ and $\mathrm{O}_{\mathrm{H}}$ atoms was fixed to the same value to form $\mathrm{OH}$ groups. The distance $\mathrm{O}_{\mathrm{H}}-\mathrm{H}$ was soft constrained to $0.93 \AA$ value. Besides, the sum of $\mathrm{OH}$ group and $\mathrm{F}$ was considered to be equal to 1 by formula unit. The same Biso value for $\mathrm{F}$ and $\mathrm{O}_{\mathrm{H}}$ atoms was considered.

CIF files for FApMn and FApMnSi have been deposited at joint CCDC/Fiz Karlsruhe deposition service with deposition numbers CSD-2038881 and CSD-2038882, respectively. Structure data can be retrieved through their Access Structure service at https://www.ccdc.cam.ac.uk/structures.

Table S6. Selected interatomic distances $(\AA)$ in FApMn and FApMnSi fluoroapatites from neutron powder diffraction data.

\begin{tabular}{|c|c|c|}
\hline & FApMn & FApMnSi \\
\hline M-O1 & $1.720(6)$ & $1.694(9)$ \\
M-O2 & $1.636(5)$ & $1.632(6)$ \\
M-O3x2 & $1.658(3)$ & $1.663(3)$ \\
& & \\
Sr1- O1 x3 & $2.545(3)$ & $2.536(3)$ \\
Sr1-O2 x3 & $2.617(3)$ & $2.641(2)$ \\
Sr1- O3 x3 & $2.945(2)$ & $2.933(3)$ \\
& & \\
Sr2-F & $2.423(3)$ & $2.431(3)$ \\
Sr2-OH & $2.461(3)$ & - \\
Sr2-O1 & $2.718(4)$ & $2.767(4)$ \\
Sr2-O2 & $2.520(3)$ & $2.516(4)$ \\
Sr2-O3 x2 & $2.5549(18)$ & $2.5450(19)$ \\
Sr2-O3x2 & $2.608(3)$ & $2.632(3)$ \\
\hline
\end{tabular}

Table S7. Comparison of cell parameters and Sr2-(F, OH) bond distances

\begin{tabular}{|c|c|c|c|}
\hline & $\mathbf{a}(\AA)$ & $\mathbf{c}(\AA)$ & $\mathbf{S r} 2-(\mathbf{O H}, \mathbf{F})(\AA)$ \\
\hline HApMn & $9.95293(9)$ & $7.45231(9)$ & $2.503(3)$ \\
\hline FApMn & $9.90381(9)$ & $7.44188(9)$ & $2.443(3)$ \\
\hline HApMnSi & $9.95720(16)$ & $7.44779(16)$ & $2.508(5)$ \\
\hline FApMnSi & $9.90213(11)$ & $7.44471(11)$ & $2.431(3)$ \\
\hline
\end{tabular}




\section{Magnetic behavior of HApMn and FApMn apatites.}

The magnetic behaviors of the Si-free apatites with or without fluorine (HApMn and FApMn) are very similar (Figures S9 and S10). The paramagnetic moments are 2.9 $\mu_{\mathrm{B}} /$ f.u. for HApMn and $2.82 \mu_{\mathrm{B}} /$ f.u. for the fluorinated one (FApMn) (Table S8). The short-range correlations are also weakly antiferromagnetic, with $\Theta$ values around -11 to $-18 \mathrm{~K}$. The predominant paramagnetic behavior is very similar to the Si-apatite samples detailed above, as well as the magnetization curves that show a paramagnetic behavior at $200 \mathrm{~K}$ and a rather weak ferromagnetic component at $5 \mathrm{~K}$.

Table S8. Paramagnetic moments calculated and Curie-Weiss temperatures for HApMn and FApMn apatites.

\begin{tabular}{|l|l|l|}
\hline & $\begin{array}{c}\text { Paramagnetic moment } \\
(\mu \mathrm{B} / \mathrm{uf})\end{array}$ & $\begin{array}{l}\text { Curie-Weiss } \\
\text { Temperature } \Theta(\mathrm{K})\end{array}$ \\
\hline HApMnSi & 3.0 & -4.1 \\
\hline FApMnSi & 2.63 & -0.9 \\
\hline HApMn & 2.9 & -11 \\
\hline FApMn & 2.82 & -18 \\
\hline
\end{tabular}
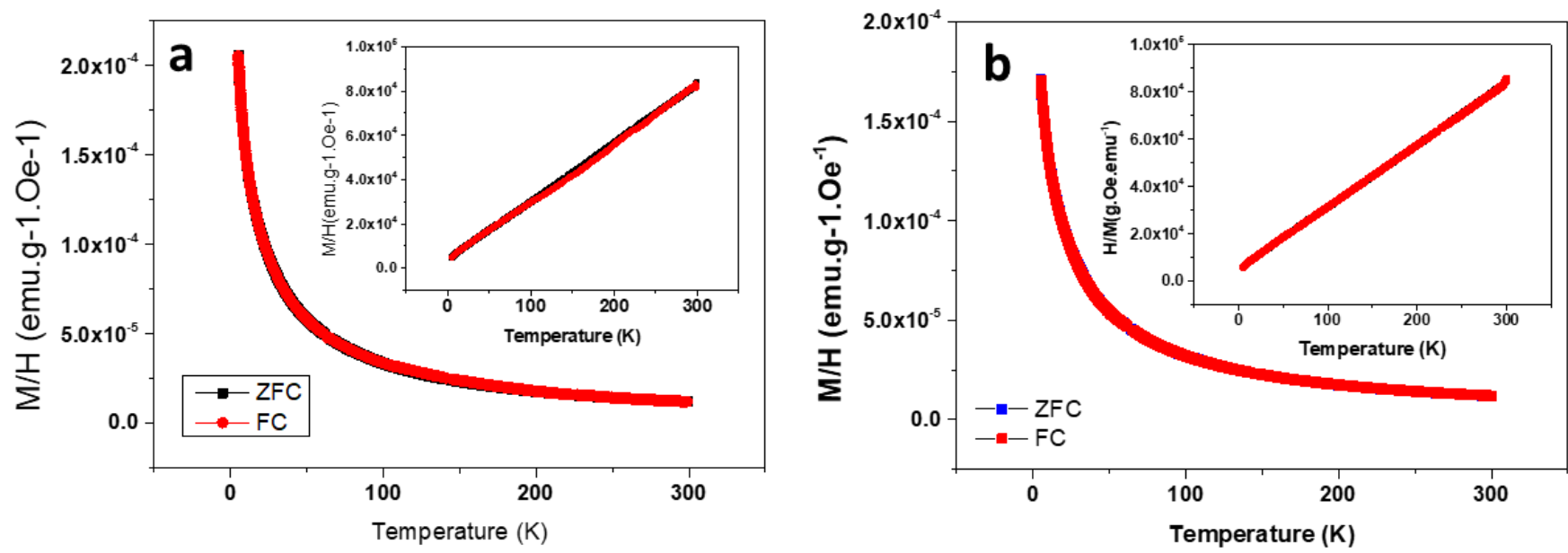

Figure S9. Temperature dependence of the magnetic susceptibility for (a) HApMn and

(b) FApMn 

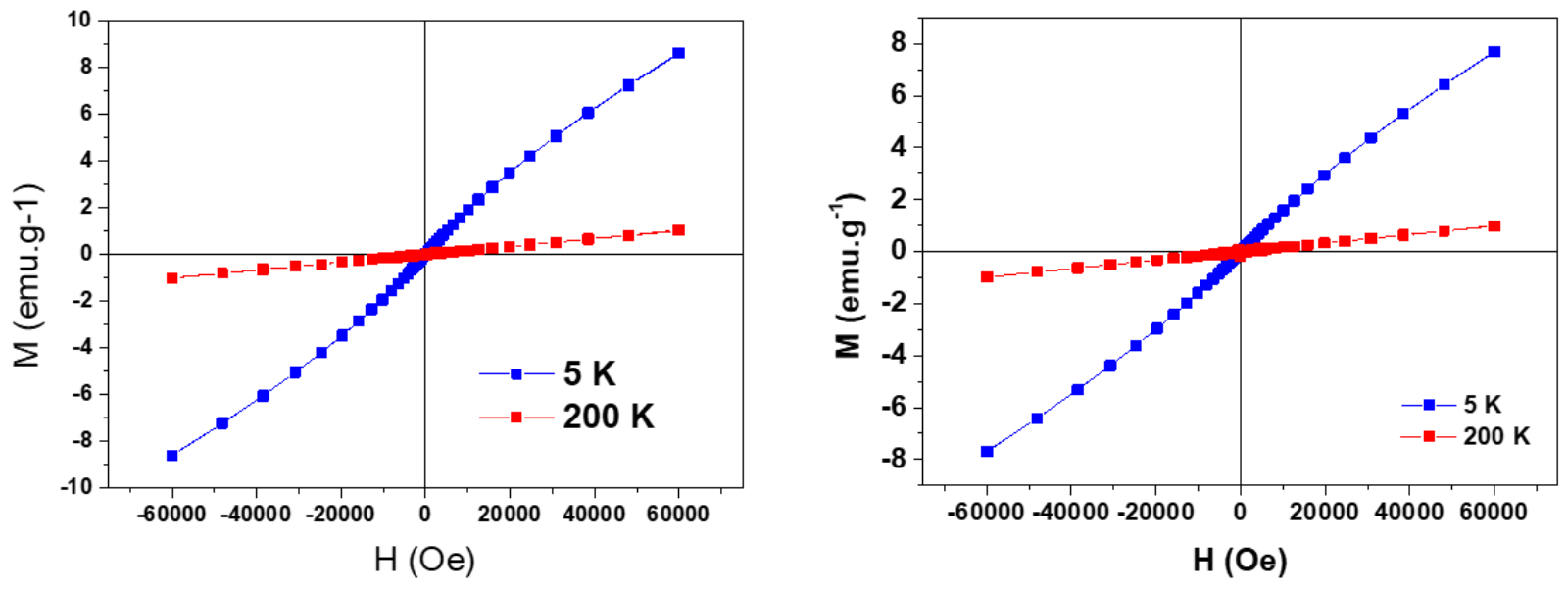

Figure S10. Field dependence of the magnetization at 5 and $200 \mathrm{~K}$ for (a) HApMn and (b) FApMn. 


\section{Thermal stability study}

The results of the thermogravimetric analysis, TGA, of the $\mathrm{Sr}_{5}\left(\left(\mathrm{Mn}_{0.947(6)} \mathrm{Si}_{0.053(6)}\right) \mathrm{O}_{4}\right)_{3}(\mathrm{OH})_{0.82(2)}(\mathrm{HApMnSi})$ sample, are presented in Figure $\mathrm{S} 11$. The TG curve under air and up to $1100{ }^{\circ} \mathrm{C}$ is shown in Figure S11a. The sample displays a slight weight loss $(\Delta \mathrm{w}=1.65 \%)$ from room temperature up to $350^{\circ} \mathrm{C}$. Above this temperature the weigh remains constant until $725^{\circ} \mathrm{C}$. On further heating, a "broad" weight loss occurs, corresponding to a $\Delta \mathrm{w}=4.55 \%$. The XRD pattern of final powder is presented in figure $\mathrm{S} 11 \mathrm{~b}$. The more intense reflections can be indexed on the basis of the triclinic unit cell of $\mathrm{Sr}_{7} \mathrm{Mn}_{4} \mathrm{O}_{15}$ mixed oxide ( $\mathrm{PDF}^{5}$ 04-010-7314), besides a small amount of $\mathrm{Sr}_{2} \mathrm{SiO}_{4}$ (PDF 00-039-1256).
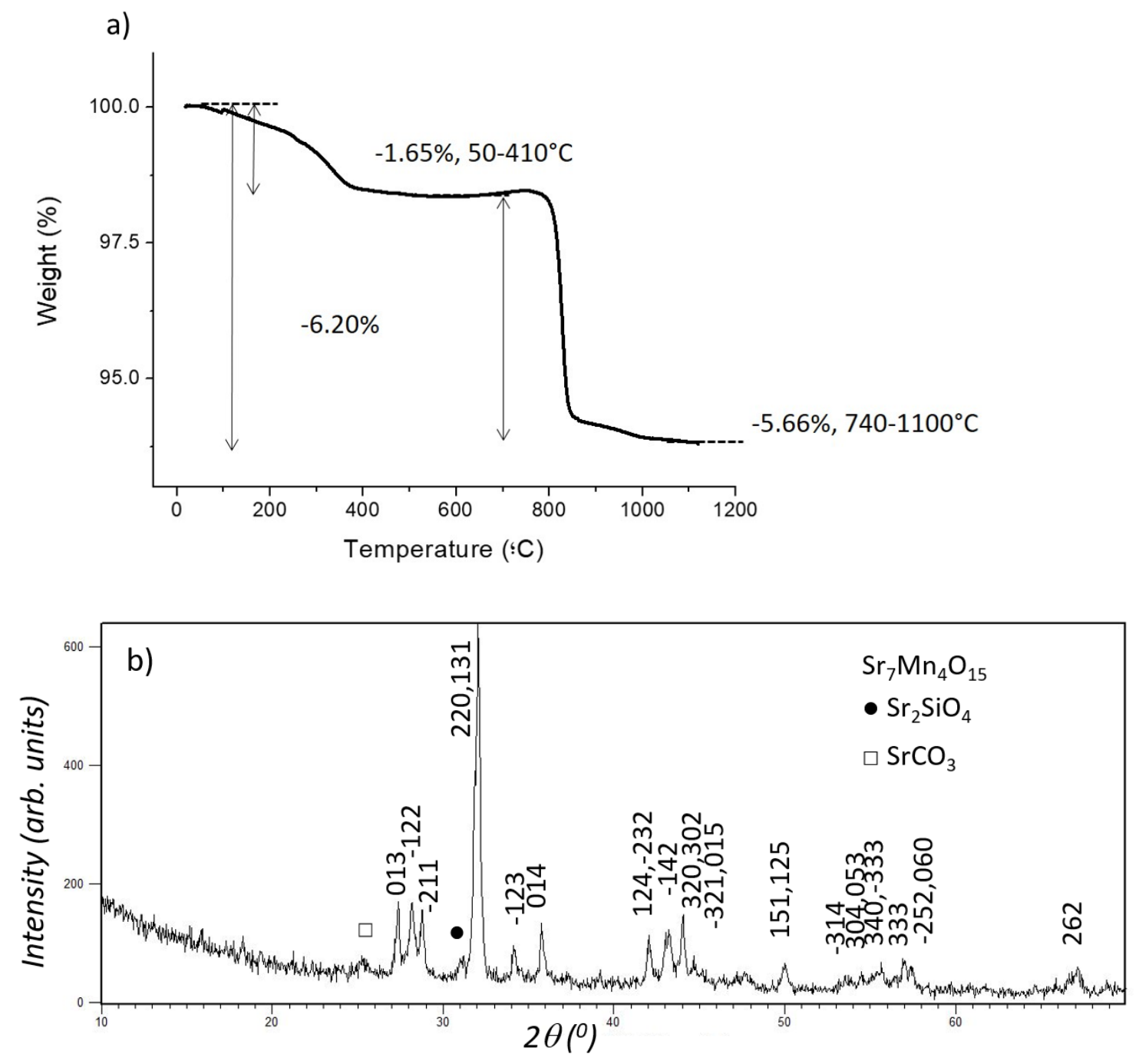

Figure S11. (a) Thermogravimetric curve of HApMnSi sample. (b) XRD pattern of the resulting product after the TGA experiment.

\footnotetext{
${ }^{5}$ Gates-Rector, S.; Blanton, T. The Powder Diffraction File: A Quality Materials Characterization Database. Powder Diffr. 2019, 34 (4), 352-360. https://doi.org/10.1017/S0885715619000812
} 
The thermal evolution of the sample has been studied by in situ high-temperature XRD (HT-XRD). The experiment consists in increasing the sample temperature in still air from room temperature (indicated by RT-1 in Figure S12) up to $1100{ }^{\circ} \mathrm{C}$. Subsequently, once a temperature of $1100{ }^{\circ} \mathrm{C}$ was reached, a cooling down process to RT was carried out (indicated by RT-2 in Figure S12). The apatite structure is maintained up to T $\sim 725^{\circ} \mathrm{C}$. Above this temperature, extra reflections corresponding to $\mathrm{Sr}_{7} \mathrm{Mn}_{4} \mathrm{O}_{15}$, are visible indicating the decomposition process of the apatite phase. This process occurs very quickly so that above $825^{\circ} \mathrm{C}$ only the apatite decomposition products $\left(\mathrm{Sr}_{7} \mathrm{Mn}_{4} \mathrm{O}_{15}\right.$ and $\mathrm{Sr}_{2} \mathrm{SiO}_{4}$ ) are observed. This result helps us to understand the TG curve described above. The first weight loss is associated to a dehydration process ( 0.24 water molecules/unit formula) since no structural change occurs in this temperature range. The system remains single phased until $725^{\circ} \mathrm{C}$ above which the hydroxyapatite begins to decompose. The decomposition process is accomplished at about $950{ }^{\circ} \mathrm{C}$ to which only $\mathrm{Sr}_{7} \mathrm{Mnn}_{4} \mathrm{O}_{15}$ and $\mathrm{Sr}_{2} \mathrm{SiO}_{4}$ (traces) are detected in the corresponding XRD pattern. The total weight loss $(\sim 4.6 \%)$ between 725 and $1100{ }^{\circ} \mathrm{C}$ perfectly agrees with this process.

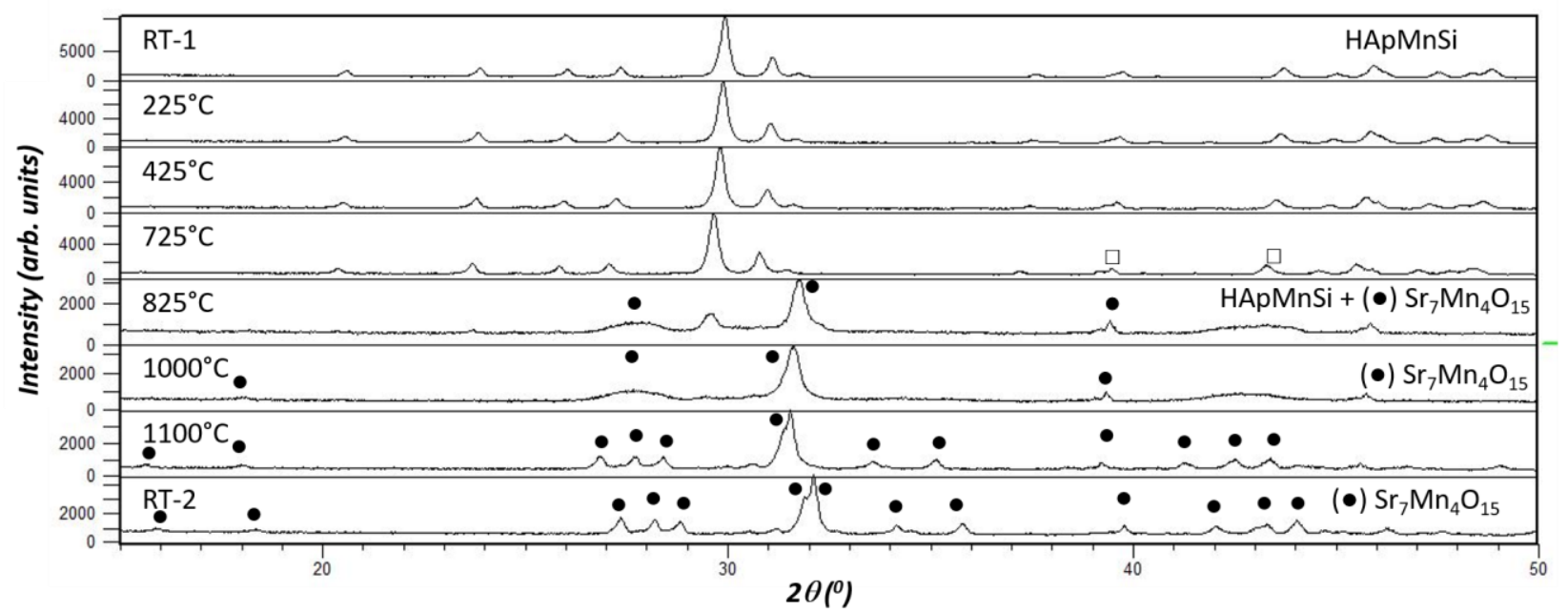

Figure S12. In situ high temperature XRD study of the HApMnSi sample.

The corresponding fluorinated phase shows the same thermal behavior. FApMnSi remains stable up around $725^{\circ} \mathrm{C}$. Above this temperature, the sample begins to decompose following the same pathway as the one described above for HApMnSi.

In a similar way, the thermal evolution of the samples without $\mathrm{Si}, \mathrm{HApMn}$ and FApMn samples, have been also investigated. The TGA and HT-XRD results for HApMn are shown in Figures S13 and S14. The apatite without silicon HApMn is less stable than the fluorinated one $\mathrm{HApMnSi}$. Although upon decomposition, $\mathrm{Sr}_{7} \mathrm{Mn}_{4} \mathrm{O}_{15}$ is also obtained, the pathway of the reaction is quite different. Indeed, HApMn $\mathrm{Sr}_{5}\left(\mathrm{MnO}_{4}\right)_{3}(\mathrm{OH})$ is only stable up to about $425{ }^{\circ} \mathrm{C}$. Above this temperature, the decomposition starts as reflected in the corresponding XRD pattern by the presence of a 
small amount of $\mathrm{SrCO}_{3}$. Therefore, the observed weight gain $(\sim 7.1 \%)$ in the TGA curve could be due to $\mathrm{CO}_{2}$ absorption. The decomposition of the starting material occurs in such a way that, at about $550{ }^{\circ} \mathrm{C}$, the formation of $\mathrm{Sr}_{4} \mathrm{Mn}_{3} \mathrm{O}_{10}$ (PDF 01-089-6885) is evident in the corresponding XRD pattern. Close to $625^{\circ} \mathrm{C}$, the starting material has fully decomposed into $\mathrm{Sr}_{4} \mathrm{Mn}_{3} \mathrm{O}_{10}$ and $\mathrm{SrCO}_{3}$. This step is accompanied by a weight loss of $\sim 3 \%$. Finally, close to $725^{\circ} \mathrm{C}$, the mixture of $\mathrm{SrCO}_{3}$ and $\mathrm{Sr}_{4} \mathrm{Mn}_{3} \mathrm{O}_{10}$ reacts yielding $\mathrm{Sr}_{7} \mathrm{Mn}_{4} \mathrm{O}_{15}$ as the only reaction product above $825^{\circ} \mathrm{C}$. This phase remains stable during cooling down to room temperature (RT-2 in figure S14).
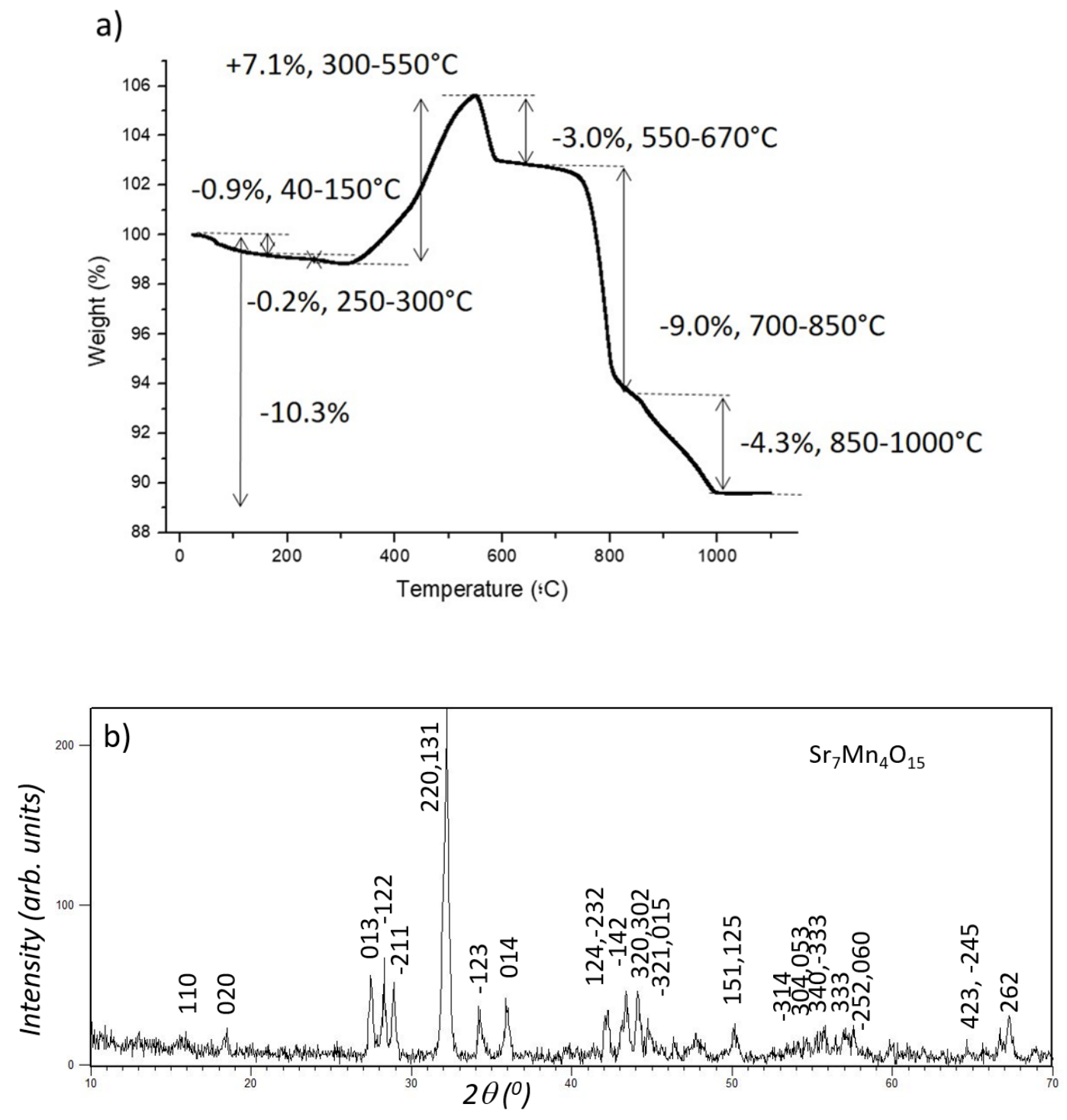

Figure S13 (a) Thermogravimetric curve for HApMn. (b) XRD pattern of the resulting product of the TGA experiment. 


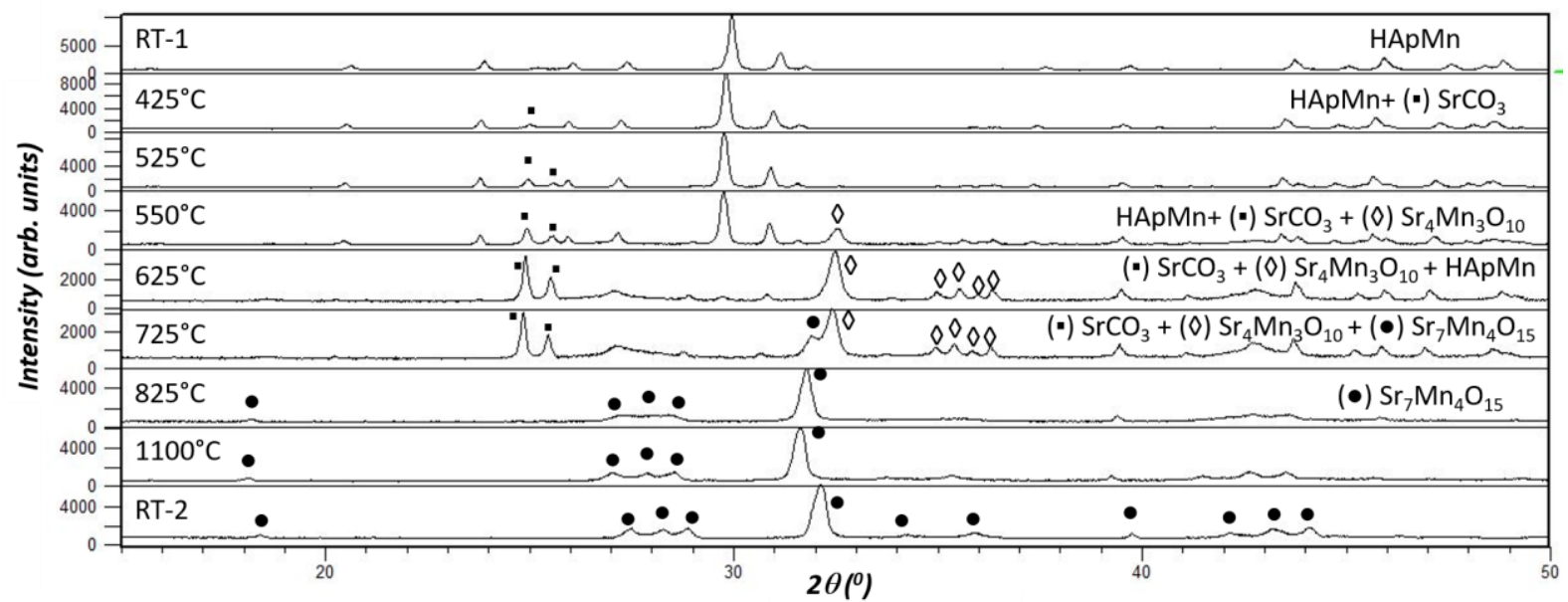

Figure S14. In situ high temperature XRD study of the HApMn sample.

The corresponding fluorinated phase, FApMn, is thermally stable up about $500{ }^{\circ} \mathrm{C}$. From this temperature, the sample decomposes through the same pathway as described above for the HApMn hydroxyapatite. 

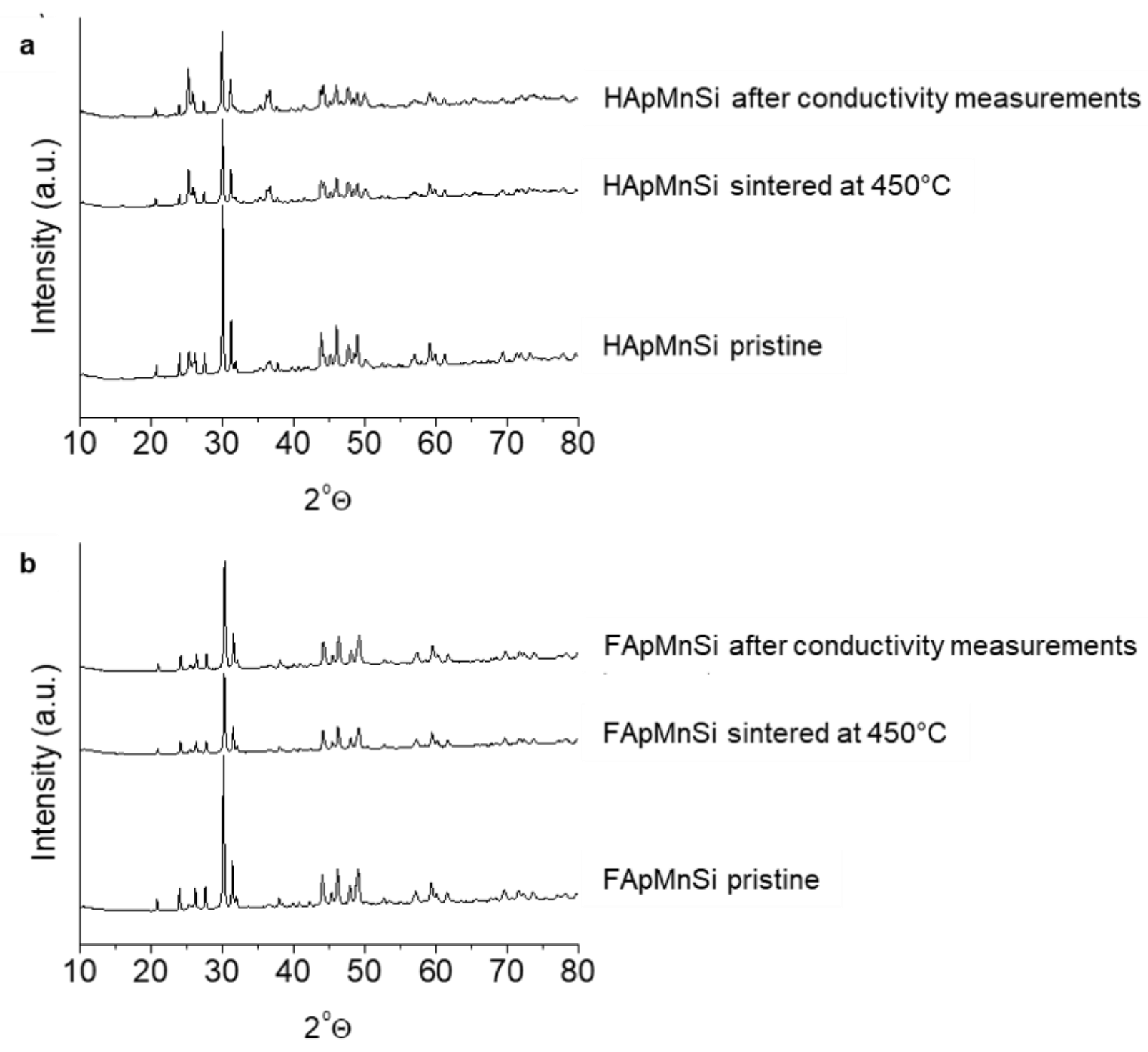

Figure S15. XRD of pelletized (a) HApMnSi and (b) FApMnSi fresh, calcined at $450{ }^{\circ} \mathrm{C}$ for 8 hours and after the conductivity measurements. 